\title{
STATUS OF URINARY 15-F2t-ISOPROSTANE LEVELS IN GENERALIZED TONIC-CLONIC SEIZURE PATIENTS WITH LEVETIRACETAM IN A TERTIARY CARE HOSPITAL
}

\author{
BHUVANESHWARI ${ }^{1 *}$, VIJAYA D ${ }^{2}$ \\ ${ }^{1}$ Department of Pharmacology, KMCH Institute of Health Sciences and Research, Coimbatore, Tamil Nadu, India. ${ }^{2}$ Department of \\ Biochemistry, PSG Institute of Medical Sciences and Research, Coimbatore, Tamil Nadu, India. Email: bhuvana1421@gmail.com
}

Received: 07 October 2020, Revised and Accepted: 23 November 2020

\section{ABSTRACT}

Objectives: The objective of the study was to analyze urinary 15-2t-isoprostane levels in epileptic patients with levetiracetam (LEV) and to compare the urinary 15-2t-isoprostane levels between the different age groups, smokers, and alcoholics.

Method: The study was conducted in a tertiary care hospital. Urinary 15-2t-isoprostane levels were assayed in epileptic patients taking LEV. Twenty patients were recruited. Urinary levels of 15-F2t-isoprostane determined by ELISA. The patient's age, gender, height, weight, smoking, and alcoholic history were collected using pro forma. Statistical analysis of data was performed using SPSS version 23.0 .

Results: A total of 20 participants recruited for the study. Among these, $70 \%$ were male and $30 \%$ were female. The mean weight and height were more in males compared to females. The mean 15-F2t-isoprostane level was significantly higher in males compared to females. More than $40 \%$ of the participants were in the age group of $>40$ years. However, the mean urinary 15-F2t-isoprostane level is higher in the age group of 19-30 years. Only $20 \%$ of the participants were smokers and alcoholics. Non-smokers and non-alcoholics had higher urinary 15-F2t-isoprostane levels compared to smokers and alcoholics.

Conclusion: The urinary 15-F2t-isoprostane levels were more in males, the age group of 19-30 years, non-smokers and non-alcoholics. However, the levels are lesser when compared to earlier meta-analysis study. This concludes that LEV may have antioxidant effect. There is a need for further studies with more sample size and correlation of LEV and urinary 15-F2t-isoprostane levels.

Keywords: Levetiracetam, Urinary 15-F2t-isoprostane levels, Generalized tonic-clonic seizure, Epilepsy.

(C) 2021 The Authors. Published by Innovare Academic Sciences Pvt Ltd. This is an open access article under the CC BY license (http://creativecommons.org/ licenses/by/4.0/) DOI: http://dx.doi.org/10.22159/ajpcr.2021v14i1.39945. Journal homepage: https://innovareacademics.in/journals/index.php/ajpcr

\section{INTRODUCTION}

Epilepsy is a severe neurologic disorder associated with stigma, psychiatric comorbidity, and high economic costs. The WHO's 2010 Global Burden of Disease study ranks epilepsy as the second most troublesome neurologic disease worldwide in terms of disabilityadjusted life years [1]. The incidence of epilepsy is predominantly high in children under 5 years of age and in individuals older than 65 years [2,3]. About one-fourth of all cases develop before the age of five [4]. Nowadays, a growing consideration is paid to the probable interrelationship between oxidative stress resultant in disorder of physiological signaling roles of calcium and free radicals in neuronal cells and mitochondrial dysfunction, cell damage, and epilepsy. The positive stimulation of mitochondrial calcium signals by reactive oxygen species and increased reactive oxygen species generation subsequent from augmented mitochondrial calcium can clue to a positive feedback loop. We suggest that calcium can produce both physiological and pathological effects of mitochondrial function, which can lead to neuronal cell death and subsequent epileptic seizures. Various antiepileptic drugs may retard the endogenous antioxidative capacity to avoid oxidative stress. The pro-oxidative properties of these antiepileptic drugs might lead to augmentation of seizure activity, leading to loss of their efficacy [5]. There was an increase in urinary $15 \mathrm{~F}-2 \mathrm{t}$-isoprostane levels in epileptic patients who were treated with levetiracetam (LEV) which may indicate that LEV induces the oxidative stress in epileptic patients [6]. In the past 25 years, 14 new antiepileptic medications (AEMs) have entered the market [7]. LEV is a novel anticonvulsant structurally unrelated to other AEMs [8]. Therefore, this study is needed to determine the effects of LEV, an anticonvulsant, on the antioxidant enzyme activities (See comment in PubMed Commons below).
Aims and Objectives

The objective of the study was to analyze urinary 15-2t-isoprostane levels in epileptic patients with LEV and to compare the urinary 15-2t-isoprostane levels between the different age groups, smokers, and alcoholics.

\section{METHODOLOGY}

A cross-sectional study was conducted on the patients visited the tertiary care hospital at Tamil Nadu, India, from August 2017 to July 2018 after approval from the Institutional Human Ethics Committee. Patient's above 18 years, both gender, having LEV $500 \mathrm{mg}$ twice daily for more than 1 month, diagnosed as idiopathic generalized tonicclonic seizure was included in the study. Patients with a history of seizure within 1 month, abnormal neurological examination, known abnormal cerebral MRI scan, endocrinopathies, liver, heart, kidney diseases, cancer, and any disease likely to affect lipid metabolism, any inflammatory disease, and renal and hepatic failure were excluded from the study. Written informed consent was obtained from eligible patients based on inclusion and exclusion criteria. Five milliliters of urine samples were collected from the participants. The urine samples were stored at $-80^{\circ} \mathrm{C}$ until analyzed. Urinary levels of $15-\mathrm{F} 2 \mathrm{t}-$ isoprostane determined by ELISA. Each sample was analyzed twice for urinary levels of 15-F2t-isoprostane. The patient's age, gender, height, weight, smoking, and alcoholic history were collected using pro forma.

Urinary 15-F2t-isoprostane immunoassay

Urinary 15-F2t-isoprostane levels were analyzed using immunoassay kits from Neogen Corporation (Product number \#430110). The procedure of assay was done in ELISA according to product leaflet. Urinary 15-F2t-isoprostane level was expressed as ng/mg Cr. 
Table 1: Gender and age distribution of participants

\begin{tabular}{|c|c|c|c|c|c|}
\hline \multirow[t]{2}{*}{ Gender and age group } & \multirow[t]{2}{*}{ Total participants $\mathrm{n}(\%)$} & \multirow[t]{2}{*}{ Mean weight (kg) } & \multirow[t]{2}{*}{ Mean height $(\mathrm{cm})$} & \multicolumn{2}{|c|}{ Urinary 15-F2t-isoprostane level } \\
\hline & & & & Mean (ng/mg Cr) & p-value \\
\hline Total & $20(100)$ & 61.8 & 157.5 & 0.27 & \\
\hline Female & $6(30)$ & 55.1 & 153 & 0.15 & \\
\hline 19-30 years & $6(30)$ & 56.6 & 158 & 1.11 & 0.400 \\
\hline $31-40$ years & $6(30)$ & 63.6 & 159.7 & 0.33 & \\
\hline$>40$ years & $8(40)$ & 64.4 & 155.5 & 0.27 & \\
\hline
\end{tabular}

${ }^{*} \mathrm{p}<0.05$ is statistically significant

Table 2: Smoking and alcoholic status of participants

\begin{tabular}{|c|c|c|c|}
\hline \multirow[t]{2}{*}{ Status of participants } & \multirow[t]{2}{*}{ Total participants n (\%) } & \multicolumn{2}{|c|}{ Urinary 15-F2t-isoprostane level } \\
\hline & & Mean (ng/mg Cr) & p-value \\
\hline Smoker & $4(20)$ & 0.39 & 0.299 \\
\hline Alcoholic & $4(20)$ & 0.27 & 0.170 \\
\hline Non-alcoholic & $16(20)$ & 0.61 & \\
\hline
\end{tabular}

\section{Statistical analysis}

Statistical analysis of data was performed using SPSS version 23.0. Mean urinary 15-F2t-isoprostane levels were compared by unpaired Student's t-test between males and females, smokers and non-smokers, and alcoholics and non-alcoholics. Single factor ANOVA was used to compare between three different age groups. $\mathrm{p}<0.5$ was considered as statistically significant.

\section{RESULTS}

A total of 20 participants recruited for the study. Among these, 70\% were male and $30 \%$ were female. The mean weight and height were more in males compared to females. The mean 15-F2t-isoprostane level was significantly higher in males compared to females (Table 1). More than $40 \%$ of the participants were in the age group of $>40$ years. The age group $>40$ showed higher mean body weight than other age groups. However, the mean urinary 15-F2t-isoprostane level is higher in the age group of 19-30 years. However, it was not statistically significant (Table 1).

Only $20 \%$ of the participants were smokers and alcoholics. Nonsmokers and non-alcoholics had higher urinary 15-F2t-isoprostane levels compared to smokers and alcoholics. However, it was not statistically significant (Table 2).

\section{DISCUSSION}

A previous study on LEV had reported increased 15F-2t-isoprostane levels in the 21 patients ( 11 were female and 10 males) [9]. The present study was done in $70 \%$ of males and $30 \%$ of females. In the meta-analysis study, mean urinary $15 \mathrm{~F}-2 \mathrm{t}$-isoprostane levels in normal patients were $1.5 \mathrm{ng} / \mathrm{mg} \mathrm{Cr}$ [10]. In the current study, mean urinary $15 \mathrm{~F}-2 \mathrm{t}$-isoprostane levels were significantly higher in males compared to females. However, in both males and females, the level was $<1.5 \mathrm{ng} / \mathrm{mg}$ Cr. Hence, this study shows that LEV may have antioxidant effect both in males and females (Table 1).

The mean urinary 15-F2t-isoprostane level is higher in the age group of 19-30 years. However, it was not statistically significant (Table 1). However, it was lesser than normal mean urinary $15 \mathrm{~F}-2 \mathrm{t}$-isoprostane levels in the earlier meta-analysis study [10]. Hence, this study shows that LEV may have antioxidant effect at all age groups.

In the current study, non-smokers and non-alcoholics showed higher urinary 15-F2t-isoprostane levels compared to smokers and alcoholics. However, it was not statistically significant (Table 2).
However, it was lesser than the mean urinary $15 \mathrm{~F}-2 \mathrm{t}$-isoprostane levels in the earlier meta-analysis study on smokers [10]. Hence, this study shows that there was no significant difference in the antioxidant status in smokers and alcoholics compared to non-smokers and nonalcoholics.

\section{CONCLUSION}

The urinary 15-F2t-isoprostane levels were more in males, the age group of 19-30 years, non-smokers and non-alcoholics. However, the levels are lesser when compared to earlier meta-analysis study [10]. This concludes that LEV may have antioxidant effect. There is a need for further studies with more sample size and correlation of LEV and urinary 15-F2t-isoprostane levels.

\section{ACKNOWLEDGMENTS}

This project has received PSG PRIME grant for the conduct of study. I would like to acknowledge Dr. Balakrishnan (Neurologist, PSG IMSR), Dr. Sumitra (Associate Professor, Department of Biochemistry, PSG IMSR), and Dr. P Mary Mala (Post graduate student, Department of Pharmacology, PSG IMSR) for their support throughout the study.

\section{AUTHORS' CONTRIBUTIONS}

Both the authors contributed for concept, design, screening of patients, selection, and recruitment of patients, informed consent, laboratory investigations, laboratory report interpretation, data collection and monitoring of data, interpretation of data, statistical analysis, and interpretation, maintaining master file of project, drafting final report, submission of final report to funding agency and IHEC, Publication.

\section{CONFLICTS OF INTEREST}

The authors declared no conflicts of interest regarding the research, authorship, and publication of this article.

\section{AUTHORS' FUNDING}

This project has received PSG PRIME grant for the estimation of urinary 15-F2t-isoprostane levels.

\section{REFERENCES}

1. Fiest KM, Sauro KM, Wiebe S, Patten SB, Kwon CS, Dykeman J, et al. Prevalence and incidence of epilepsy: A systematic review and metaanalysis of international studies. Neurology 2017;88:296-303.

2. Stefan H, Halász P, Gil-Nagel A, Shorvon S, Bauer G, BenMenachem E, et al. Recent advances in the diagnosis and treatment of 
epilepsy. Eur J Neurol 2001;8:519-39.

3. Patel M. Mitochondrial dysfunction and oxidative stress: Cause and consequence of epileptic seizures. Free Radic Biol Med 2004;37:1951-62.

4. Scott RA, Lhatoo SD, Sander JW. The treatment of epilepsy in developing countries: Where do we go from here? Bull World Health Organ 2001;79:344-51.

5. Martinc B, Grabnar I, Vovk T. The role of reactive species in epileptogenesis and influence of antiepileptic drug therapy on oxidative stress. Curr Neuropharmacol 2012;10:328-43.

6. Ozden H, Kabay SC, Toker A, Ustüner MC, Ozbayer C, Ustüner D, et al. The effects of levetiracetam on urinary $15 \mathrm{f}-2 \mathrm{t}$-isoprostane levels in epileptic patients. Seizure 2010;19:514-6.

7. LaRoche SM, Helmers SL. The new antiepileptic drugs: Clinical applications. JAMA 2004;291:615-20.

8. Klitgaard H. Levetiracetam: The preclinical profile of a new class of antiepileptic drugs? Epilepsia 2001;42:13-8.

9. Varoglu AO, Yildirim A, Aygul R, Gundogdu OL, Sahin YN. Effects of valproate, carbamazepine, and levetiracetam on the antioxidant and oxidant systems in epileptic patients and their clinical importance. Clin Neuropharmacol 2010;33:155-7.

10. Van't Erve TJ, Kadiiska MB, London SJ, Mason RP. Classifying oxidative stress by $\mathrm{F} 2$-isoprostane levels across human diseases: A meta-analysis. Redox Biol 2017;12:582-99. 